\title{
Stage-specific Embryogenic Antigen-4 Expression in Castration-resistant Prostate Cancer and its Correlation With the Androgen Receptor
}

\author{
JUNKI HARADA ${ }^{1}$, YASUYOSHI MIYATA ${ }^{1}$, TAKENOBU TAIMA ${ }^{2}$, TSUYOSHI MATSUDA ${ }^{1}$, \\ YUTA MUKAE ${ }^{1}$, KENSUKE MITSUNARI $^{1}$, TOMOHIRO MATSUO ${ }^{1}$, KOJIRO OHBA $^{1}$, \\ TETSUJI SUDA ${ }^{3}$, HIDEKI SAKAI ${ }^{1}$, AKIHIRO ITO $^{2}$ and SEIICHI SAITO ${ }^{3}$ \\ ${ }^{1}$ Department of Urology, Nagasaki University Graduate School of Biomedical Sciences, Nagasaki, Japan; \\ ${ }^{2}$ Department of Urology, Tohoku University Graduate School of Medicine, Miyagi, Japan; \\ ${ }^{3}$ Department of Urology, University of the Ryukyus, Okinawa, Japan
}

\begin{abstract}
Background/Aim: Stage-specific embryonic antigen (SSEA)-4 plays important roles in the malignant aggressiveness of various cancers. The aim of this study was to investigate the pathological characteristics of SSEA-4 in castration-resistant prostate cancer (CRPC). Materials and Methods: SSEA-4 expression and its pathological roles were evaluated in five prostate cancer $(P C)$ cell lines and 27 CRPC tissues. The relationship between SSEA-4 and the androgen receptor $(A R)$ was also examined. Results: SSEA4 expression was detected in AR-negative cells (PC3, DU145, and AICaP1) but was not detected in AR-positive cells (LNCaP and AICaP2). SSEA-4 expression in human CRPC tissues was significantly higher than that in locally advanced or metastatic hormone sensitive PC (HSPC) tissues. A negative correlation was also detected between SSEA-4 and AR in CRPC tissues but not in HSPC tissues. Conclusion: SSEA-4 was over-expressed in CRPC and the changes were mediated by complex mechanisms that related to the AR and hormonal therapy.
\end{abstract}

Prostate cancer (PC) is one of the most common cancers in men. Hormonal therapy using androgen deprivation is one of the standard therapies that is often selected as a conservative

This article is freely accessible online.

Correspondence to: Yasuyoshi Miyata, MD, Ph.D., Department of Urology, Nagasaki University Graduate School of Biomedical Sciences, 1-7-1 Sakamoto, Nagasaki 852-8501, Japan. Tel: +81 958197340, Fax: +81 958197343, e-mail: yasu-myt@ nagasaki-u.ac.jp

Key Words: Stage-specific embryonic antigen (SSEA)-4, castrationresistant prostate cancer (CRPC), androgen receptor (AR), hormonal therapy. therapy for patients with metastatic PC, advanced age, and/or severe comorbidity. However, in most cases, there are limitations to suppressing the malignant potential owing to the acquisition of resistance against hormonal therapy. Ultimately, due to the lack of androgen dependency during androgen deprivation, hormone-sensitive PC (HSPC) cells gradually transform into castration-resistant prostate cancer (CRPC) cells (1).

The prognosis of patients with CRPC has improved because of various newly developed treatment strategies (2, 3 ). However, research for novel therapeutic targets continues to further prolong the survival periods as the anti-cancer effects of current treatments are unsatisfactory. Furthermore, it is known that understanding the molecular mechanisms of androgen-independent tumor growth is essential for formulating new treatment strategies for patients with CRPC. In addition, there is a consensus that hyper-activated androgen-receptor (AR) pathways through up-regulated expression/gene mutation, presence of variants, and/or paracrine/autocrine androgen synthesis are important determinants of the pathological aggressiveness of CRPC (4, $5)$. Therefore, most prior studies on the acquisition of androgen independence have focused on AR. However, in addition to these direct pathological phenomena via AR pathways, several molecular signaling pathways have been reported to play important roles in the malignant behavior of CRPC via androgen-/AR-independent pathways $(6,7)$. Based on such information, it is concluded that understanding the interactions between $\mathrm{AR}$ and other cancer-related molecules is vital for improving the prognosis of patients with CRPC $(8,9)$.

Gangliosides, which are glycolipids containing sialic acid, play crucial roles in various cancer-related characteristics such as cell adhesion, motility, and invasion, and are used to determine prognosis and outcomes (10-12). Among them, 
monosialosyl globopentaosylceramide [MSGb5, also called stage-specific embryogenic antigen-4 (SSEA-4)] has been reported to be associated with carcinogenesis, malignant behaviors, therapeutic resistance, and survival in various malignant cells (13-16). In a previous study, we reported that SSEA-4 expression was positively associated with malignant aggressiveness, poor anti-cancer effects of neoadjuvant hormonal therapy (NHT), and worse outcome in patients with hormone-naïve PC $(17,18)$. Additionally, we found that SSEA4 expression in patients post-NHT was significantly higher than that in patients pre-NHT (18). Thus, SSEA-4 expression may be up-regulated by hormonal therapy in patients with PC.

When this possibility is considered, the following important facts should be noted: 1) in addition to androgen-dependent signaling pathways, cancer stem cells (CSCs) play important roles in the malignant aggressiveness and biological characteristics of CRPC cells $(19,20)$; 2) in both HSPC and CRPC, CSCs are associated with resistance to anti-cancer therapies, including hormonal therapy $(21,22)$; 3$)$ several CSC markers in PC cells are increased after androgen deprivation $(23,24)$; and 4) SSEA-4 has been recognized as a marker of CSCs in PC $(25,26)$. Consequently, detailed information on the pathological significance and regulatory mechanisms of SSEA-4 expression is crucial for devising novel treatment strategies for patients with PC, especially those with CRPC. However, the pathological significance of SSEA-4 in CRPC is still unclear as previous studies were performed for HSPC, and not for CRPC. Therefore, we performed in vivo and in vitro studies to clarify the biological and pathological characteristics of SSEA-4 in CRPC.

\section{Materials and Methods}

Antibodies and reagents. The mouse IgM monoclonal antibody $(\mathrm{mAb}) \mathrm{RM} 1$ has been established as the specific mAb targeting SSEA-4 (27). We purchased the following antibodies: mouse antiAR mAbs (Upstate Biotechnology, Lake Placid, NY, USA), horseradish peroxidase (HRP)-labeled rabbit anti-mouse IgM (Zymed Laboratories, South San Francisco, CA, USA), HRPlabeled rabbit anti-mouse IgG (Santa Cruz Biotechnology Inc., Santa Cruz, CA, USA), and FITC-goat anti-mouse $\operatorname{IgG}+\operatorname{IgM}(\mathrm{H}+\mathrm{L})$ (Kirkegaard \& Perry Laboratories; KPL, Middlesex, UK). We used N-Histofine ${ }^{\circledR}$ Simple Stain MAX PO (MULTI) (Nichirei Biosciences Inc., Tokyo, Japan) for immunohistochemical staining.

Cell culture. The prostate cancer cell lines PC3, DU145, and LNCaP, were purchased from American Type Culture Collection (ATCC) and they were cultured in RPMI-1640 medium containing $10 \%$ fetal bovine serum (FBS) (ICN Biomedicals, Aurora, OH, USA) at $37^{\circ} \mathrm{C}$ in a humidified atmosphere with $5 \% \mathrm{CO}_{2}$. We established two androgen-independent cell lines (AICaP1 and AICaP2) by long-term culture of androgen-sensitive LNCaP cells in phenol red-free RPMI-1640 medium supplemented with $10 \%$ charcoal:dextran stripped (CDS)-FBS (Hyclone, Logan, UT, USA). This steroid-free medium was replaced every 3-4 days for 3 months according to a method described previously (28). Cell morphology was examined via phase contrast microscopy (Axiovert 25; Carl Zeiss, Jena, Germany).

Proliferation assay. LNCaP, AICaP1, and AICaP2 cells $\left(1 \times 10^{3}\right)$ were cultured in 96-well Corning tissue culture plates. The number of cells was determined daily with a plate reader, using the Fluoroskan Ascent Labsystem (Dainippon Pharma Co., Osaka, Japan) after the addition of calcein AM solution (C-3100MP, Invitrogen, Carlsbad, CA, USA).

Wound migration assay. $\mathrm{LNCaP}, \mathrm{AICaP} 1$, and $\mathrm{AICaP} 2$ cells were incubated in 24-well Corning tissue culture plates for $24 \mathrm{~h}$ at $37^{\circ} \mathrm{C}$. Subsequently, the surface of each culture was scratched with the tip of a $10 \mathrm{ml}$ plastic pipette, washed to remove the debris, and treated with fresh culture medium. The distance between the borders $\left(t_{0}\right)$ was measured along the well using a grid and a Carl Zeiss phasecontrast inverted microscope (Axiovert 25) at 40× magnification. Experiments were performed in triplicate and the distance was measured in four fields of each well. After incubation for $24 \mathrm{~h}$ at $37^{\circ} \mathrm{C}$, the distance between the borders $\left(\mathrm{t}_{\text {final }}\right)$ was measured again in each field. The speed of migration was calculated as the distance by which the cells advanced from both borders $\left(\mathrm{t}_{\mathrm{g}}-\mathrm{t}_{\text {final }}\right)$ at the marked points divided by 2 , and expressed as $\mathrm{mm} / \mathrm{h}$.

Matrigel invasion assay. $\mathrm{LNCaP}, \mathrm{AICaP} 1$, and $\mathrm{AICaP} 2$ cells were grown in $75 \mathrm{~cm}^{2}$ culture dishes and trypsinized at $70-80 \%$ confluence. The cells were then counted and suspended in RPMI1640 medium containing $0.1 \%$ CDS-FBS $\left(2 \times 10^{5} / \mathrm{ml}\right)$. Thereafter, $100 \mathrm{ml}$ aliquots of the cell suspensions were added to the upper compartments of a 24-well Matrigel-coated Transwell chamber (8 $\mathrm{mm}$ pores), while $600 \mathrm{ml}$ of RPMI- 1640 medium containing $0.1 \%$ CDS-FBS and $50 \mathrm{mg} / \mathrm{ml}$ of fibronectin was added to each lower compartment. After allowing the cells to migrate for $48 \mathrm{~h}$, the cells remaining in the upper compartment were removed with a cotton swab. The cells that had invaded through the Matrigel and adhered to the outer (lower) surface of the membrane were fixed and stained with Giemsa stain for counting under a light microscope $(\times 100)$ in five different fields (the average number per field was calculated). Each assay was performed in triplicate.

Western blot analysis. Cell lysates were obtained from cells grown to $70 \%$ confluence. Cells cultured in $75 \mathrm{~cm}^{2}$ culture dishes were washed thrice with PBS, scraped off, collected into Pyrex tubes, and centrifuged at 1,200 rpm $(310 \times \mathrm{g})$ for $3 \mathrm{~min}$. After the supernatant was discarded, $400 \mathrm{ml}$ of lysis buffer [20 mM Tris (pH 7.4) 150 $\mathrm{mM} \mathrm{NaCl}, 2 \mathrm{mM}$ EDTA, $1 \% \mathrm{NP}-40,50 \mathrm{mM} \mathrm{NaF}, 10 \mathrm{mg} / \mathrm{ml}$ leupeptin, $1 \mathrm{mM} \mathrm{Na}_{3} \mathrm{VO}_{4}$, and $1 \mathrm{mM}$ PMSF] were added to the cell pellet. The cells were then homogenized by sonication on ice, incubated for $30 \mathrm{~min}$ at $4^{\circ} \mathrm{C}$, and centrifuged at $7,500 \mathrm{rpm}(5,282 \times \mathrm{g})$ for $15 \mathrm{~min}$ at $4^{\circ} \mathrm{C}$. Next, the supernatant was collected, and the protein concentration was assayed. Aliquots of lysates containing equal amounts of protein were boiled for $5 \mathrm{~min}$ in SDS-PAGE sample buffer [ $3 \times$ sample buffer], resolved by $10 \%$ SDS-PAGE, and transferred to polyvinylidene fluoride (PVDF) membranes (Hybond $^{\mathrm{TM}}$-P; Amersham Biosciences, Piscataway, NJ, USA). After overnight blocking with $3 \%$ bovine serum albumin (BSA) in TBST at $4^{\circ} \mathrm{C}$, the PVDF membranes were incubated overnight at $4^{\circ} \mathrm{C}$ with $1 \%$ BSA in TBST and the primary antibodies The membranes were then washed, incubated with the secondary antibodies $(1: 2,000)$, and 
developed via enhanced chemiluminescence using a WEST-one ${ }^{\mathrm{TM}}$ detection kit (iNtRON Biotechnology, Inc., Gyeonggi-do, Republic of Korea). The membranes were viewed using the LAS-1000 image analyzer (Fuji Film, Tokyo, Japan).

Analysis of gangliosides. Gangliosides were extracted according to a procedure described in previously published studies $(29,30)$. Briefly, samples of the same weight dissolved in chloroform/methanol (1:1) were spotted onto Silica gel 60 highperformance thin-layer chromatography (HPTLC) plates (Merck, Darmstadt, Germany) and developed in a chamber containing chloroform/methanol/0.2\% aqueous $\mathrm{CaCl}_{2} \quad$ (50:40:10). The expression of SSEA-4 was determined via HPTLC immunostaining with the RM1 mAb. Briefly, an HPTLC plate was immersed in high-molecular weight $0.5 \%$ poly(isobutyl methacrylate) (Aldrich Chemical Co., Milwaukee, WI, USA) in hexane/chloroform (9:1) for $40 \mathrm{~s}$, dried in air for $30 \mathrm{~min}$, blocked with $3 \%$ BSA in phosphate-buffered saline (PBS) for $1 \mathrm{~h}$, and reacted with RM1 for $2 \mathrm{~h}$ at room temperature. Subsequently, the plate was washed, incubated with $0.1 \%$ HRP-labeled rabbit anti-mouse IgM in PBS, washed again, and stained with Konica Immunostaining HRP-1000 (Konica, Tokyo, Japan).

Androgen receptor cDNA transfection into AICaP1 cells. We detected the expression of SSEA-4 in AR-negative PC cells. To determine whether the AR directly influences the level of SSEA-4 expression, we transfected AICaP1 cells with a vector containing AR cDNA. The AR cDNA ligated into pIRES2-EGFR vector plasmid was kindly provided by Prof. Isaacs (Johns Hopkins University School of Medicine) and transfected into AICaP1 cells in 6-well plates using Lipofectamine $2000^{\mathrm{TM}}$ (Invitrogen) according to the manufacturer's protocol (31). On the next day, $800 \mathrm{mg} / \mathrm{ml}$ of G-418 was added to the culture medium to select transfected cells called AICaP1-AR. AR expression by AICaP1-AR cells was confirmed using western blotting.

Patients with CRPC and NHT specimen data. The expression levels of SSEA-4 and AR were investigated in 27 patients diagnosed with CRPC. Additionally, we used the data on SSEA-4 expression in preNHT tissues $(n=60)$ and post-NHT tissues $(n=60)$ from a previously published report (18). The median (interquartile range) duration of NHT was 7 months (4-10 months), and detailed information on these tissues is available in our previous reports $(18,32)$. PC tissues judged as non-adenocarcinoma, such as neuroendocrine carcinoma or small cell carcinoma, were excluded from this study population. This study design complied with the principles of the Declaration of Helsinki and its revision and was approved by the Institutional Review Board of Nagasaki University Hospital (No: 16K15690). Additionally, written informed consent was obtained from all patients.

Immunohistochemistry. Immunohistochemical staining for SSEA-4 was carried out using formalin-fixed paraffin-embedded specimens of PC tissues. SSEA-4 expression level was classified into the following four groups according to the staining intensity and percentage of positively stained PC cells: none $(-)$, mild $(+)$, moderate $(++)$, and strong $(+++)$. The detailed methods used for immunohistochemistry and evaluation have been described in our previous reports $(17,18)$. AR expression was also immunohistochemically investigated in the same PC specimens. Anti-AR mouse monoclonal antibody (sc-7350) and EnVision
Detection System (K5007) were purchased from Santa Cruz Biotechnology, Inc. (Santa Cruz, CA, USA) and Dako (Glostrup, Denmark), respectively. Immunohistochemical analyses were performed in accordance with a previously published report (33). Briefly, endogenous peroxidase activity was blocked by $3 \%$ hydrogen peroxide for $30 \mathrm{~min}$, and antigen retrieval was performed in citrate buffer at $100^{\circ} \mathrm{C}$ for $30 \mathrm{~min}$. The sections were then incubated overnight with the anti-AR antibody at $4^{\circ} \mathrm{C}$. The immunoreactive score (IRS; values 0-12) was calculated as the product of staining intensity (none $=0$, weak $=1$, moderate $=2$, and strong=3) and proportion of positive cells $(0-5.0 \%=0,5.1-25 \%=1$, $25.1-50.0 \%=2,50.1-75 \%=3$, and $75.1-100 \%=4)$. Slides were evaluated at different times by two investigators (YM and TM), who were blinded to the clinicopathological features. The mean of the values provided by these investigators was used as the IRS. In this study, AR expression was classified into 3 groups: low (IRS=0-5), middle (6-8), and high (9-12) based on its interquartile range.

Statistical analyses. The chi-square test was used for categorical comparison of the data. The Scheffé test was used for multiple comparisons of the data. All data are expressed as mean (SD), and significance was defined as $p<0.050$. All statistical analyses were performed on a personal computer with the statistical package, StatView for Windows (version 5.0; Abacus Concept Inc, Berkeley, CA, USA).

\section{Results}

Expression levels of PSA, AR, and SSEA-4 in the prostate cancer cell lines. We examined the expression of AR in five PC cell lines (LNCaP, PC3, and DU145, AICaP1 and AICaP2). Neither AR nor PSA was detected in PC3, DU145, and AICaP1 cells, whereas both molecules were detected in AICaP2 and LNCaP cells (Figure 1A). Thus, the AR-related characteristics were found to differ between AICaP1 and AICaP2 cells. Subsequently, SSEA-4 was found to be expressed in PC3, DU145, and AICaP1 cells, but not in LNCaP and AICaP2 cells (Figure 1A). Altogether, SSEA-4 was detected in the AR-negative PC cell lines (PC3, DU145 and $\mathrm{AICaP} 1$ ), but not in the AR-positive cell lines (LNCaP and $\mathrm{AICaP} 2$ ).

Based on these findings, we transfected AR cDNA into AICaP1 cells to determine whether the AR had a direct influence on the expression of SSEA-4. After AR cDNA was transfected into AR-negative AICaP1 cells, AR expression by AICaP1-AR cells was confirmed. However, SSEA-4 expression remained unaltered in AICaP1-AR cells compared to that in AICaP1 cells (Figure 1B).

Pathobiological characteristics of AICaP1 and AICaP2 cells. We examined the pathobiological characteristics of two androgen-independent PC cell lines, that is, AR-negative $\mathrm{AlCaP} 1$ and AR-positive AlCaP2 cells used to identify the pathological characteristics of androgen-independent PC cells in previous reports (34), but their detailed biological characteristics and pathological roles remained unclear. 
A

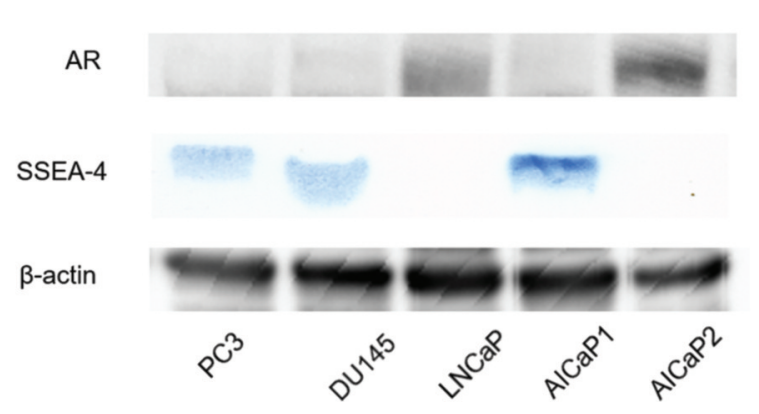

B

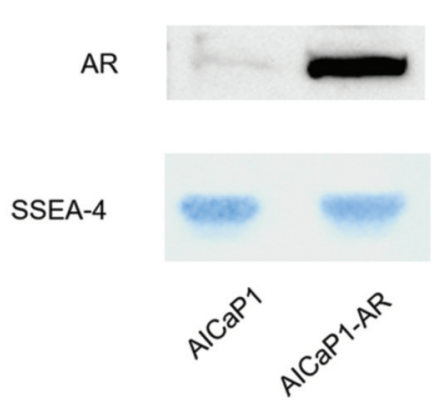

Figure 1. SSEA-4 expression in prostate cancer cell lines. (A) Comparison of androgen receptor (AR) and stage-specific embryonic antigen-4 (SSEA4) expression among prostate cancer cell lines. AR was analyzed via western blotting and SSEA-4 was examined via HPTLC immunostaining. (B) Change in SSEA-4 expression by transfection of AR cDNA into AICaP1.
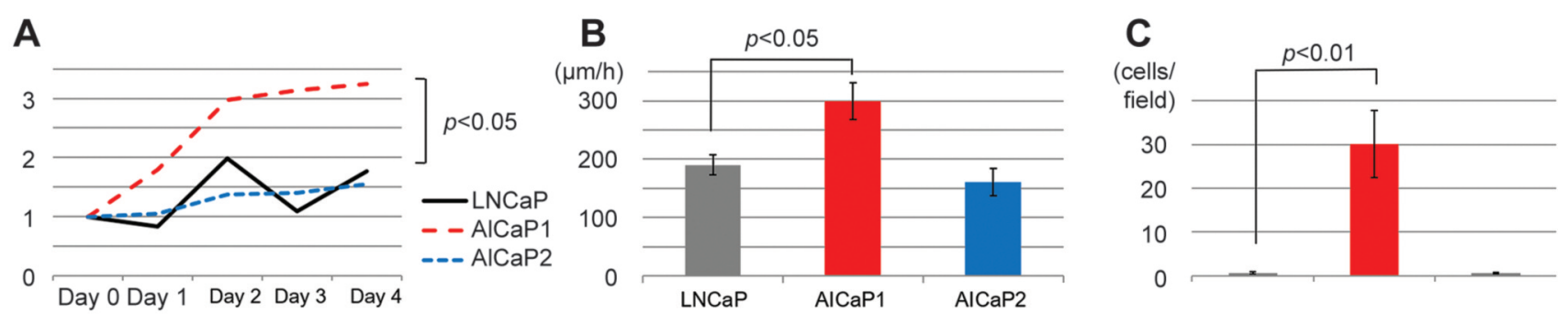

Figure 2. Cell proliferation (A), motility (B), and invasion (C) assays carried out with LNCaP, AICaP1, and AICaP2 cells.

Therefore, we evaluated them in various in vitro studies. Subsequently, the obtained growth curves revealed that the proliferation of AICaP1 cells was significantly higher than that of $\mathrm{LNCaP}$ and AICaP2 cells $(p<0.05)$ (Figure 2A). Furthermore, the motility and invasive capacity of AICaP1 cells were significantly greater than those of LNCaP and AICaP2 cells $(p<0.05$ and $p<0.01$, respectively; Figure 2B and $\mathrm{C}$ ). There were no significant differences in proliferation, motility, and invasive capacities between AICaP2 cells and LNCaP cells ( $p=0.40,0.36$, and 0.86 , respectively).

SSEA-4 expression in human CRPC tissues. Representative examples of mild (+), moderate $(++)$, and strong (+++) expression of SSEA-4 in CRPC tissues are showed in Figure 3A-C, respectively. The staining distribution of SSEA-4 in CRPC tissues was similar to that found in HSPC tissues in previous studies $(17,18)$. Finally, 15 of the $27(55.6 \%)$ CRPC tissues were assessed to have strong (+++) expression of SSEA-4, and no specimen was found to have no (-) expression (Figure 4). Upon comparison of SSEA-4 expression between CRPC and HSPC tissues, we observed that SSEA-4 immunoreactivity in CRPC was significantly higher than that in T3T4NOM0 and metastatic HSPC
( $p<0.001$ and $p=0.025$, respectively; Figure 4). Likewise, regarding grade group (GG), SSEA-4 immunoreactivity in CRPC was significantly higher than that in the high-GG (Gleason score $4+4$ or more) ( $p=0.006$; Figure 4$)$.

In a previous study, we reported the expression of SSEA4 in pre-NHT and post-NHT tissues (18). In the present study, we compared SSEA-4 expression in these NHT (pre and post) and CRPC tissues (Figure 5). We found that the percentage of positively-stained $\mathrm{PC}$ cells were in the descending order of CRPC>post-NHT>pre-NHT tissues (bars in Figure 5). Furthermore, as shown via black dots in Figure 5, the number of strongly $(+++)$ stained cells was remarkably higher in CRPC than in post-NHT tissues (by $44.6 \%$ ), whereas the number in post-NHT tissues was only slightly higher than that in pre-NHT tissues (by 3.3\%). In contrast, the number of SSEA-4-negative cells (blue dots in Figure 5) rapidly decreased after NHT, with no detection in CRPC tissues.

A negative correlation between SSEA-4 and AR expression in PC tissues. The relationship between SSEA-4 expression and AR expression in CRPC tissues is shown in Table I. High IRS for AR was not found in CRPC tissues displaying 

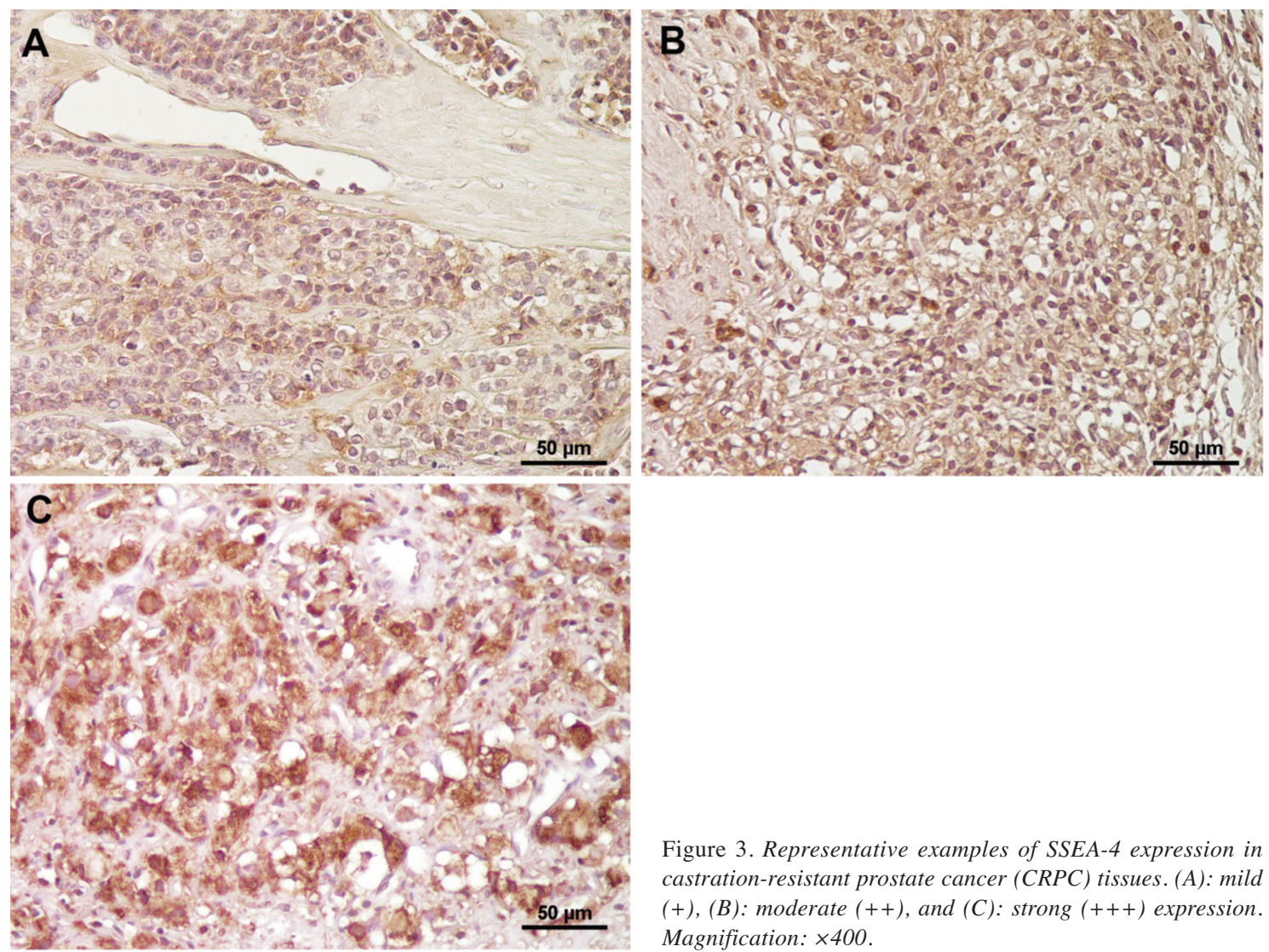

Figure 3. Representative examples of SSEA-4 expression in castration-resistant prostate cancer (CRPC) tissues. $(A)$ : mild $(+),(B)$ : moderate $(++)$, and $(C)$ : strong $(+++)$ expression. Magnification: $\times 400$.
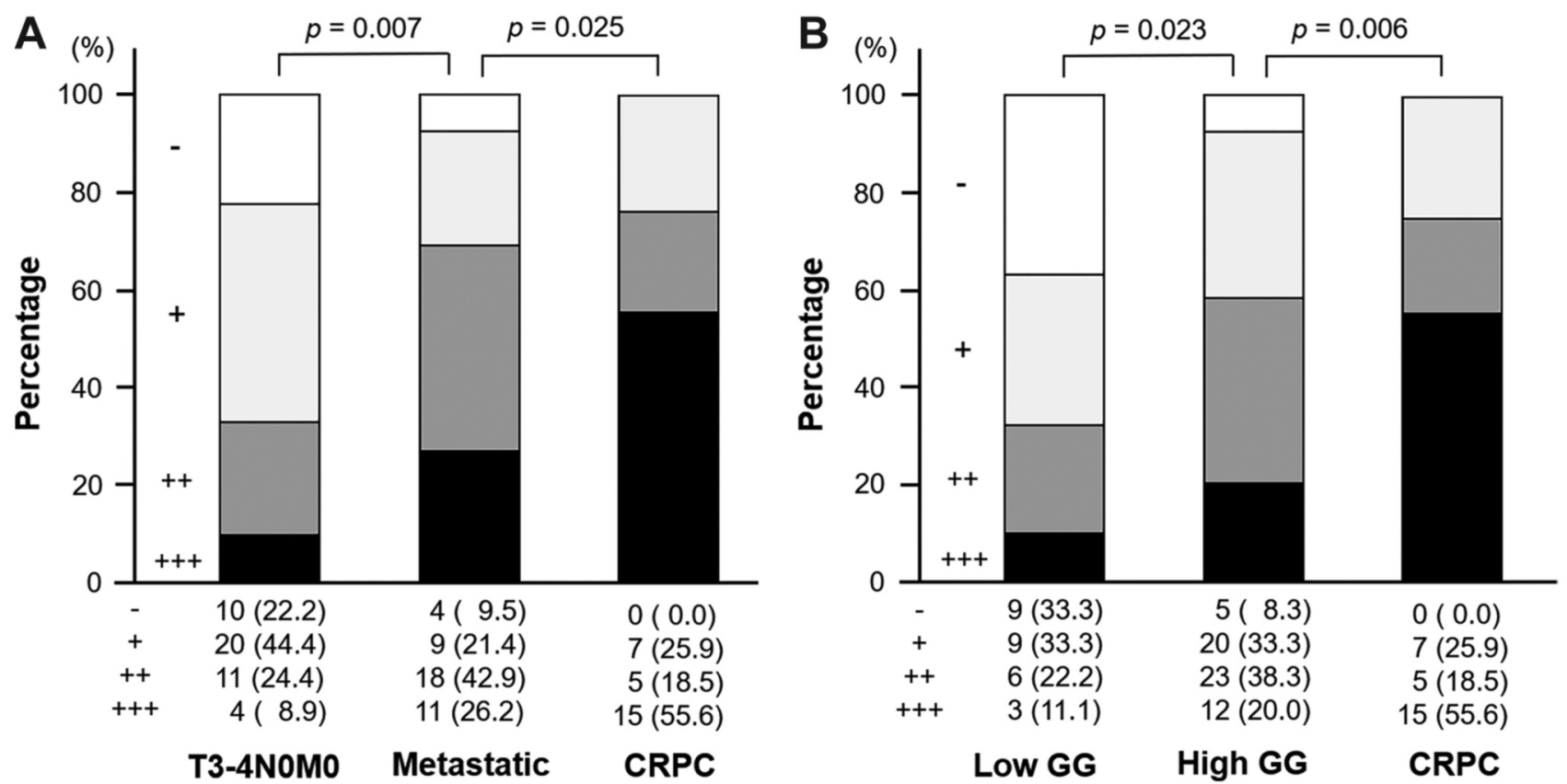

Figure 4. Comparisons of SSEA-4 expression levels between castration-resistant prostate cancer (CRPC) tissues and hormone sensitive prostate cancer (HSPC) tissues with various pathological features. SSEA-4 expression in CRPC tissues was significantly higher than that in metastatic HSPC tissues (A) and high-grade group tumors (B). 


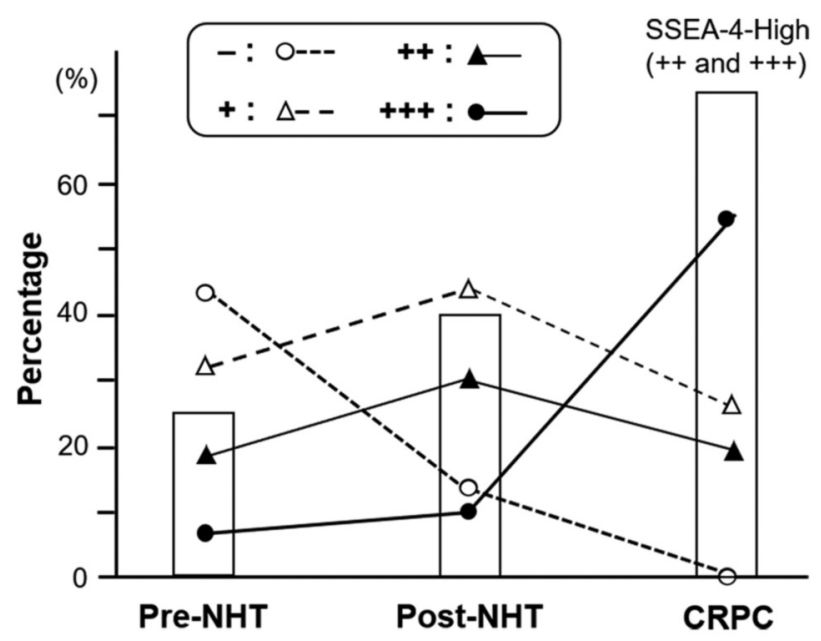

Figure 5. Comparisons of SSEA-4 expression levels among preneoadjuvant hormonal therapy (NHT), post-NHT, and CRPC tissues. Bars indicate the percentage of tissues with high SSEA-4 expression $(++$ and +++$)$. Blue round, white triangle, black triangle, and red circle dot represent - (none), + (mild), ++ (moderate $)$, and +++ (strong) expression of SSEA-4, respectively. Data on the ratios of preNHT and post-NHT tissues were acquired from our previous report (18).

strong SSEA-4 expression. Contrastingly, five of the seven CRPC tissues with mild SSEA-4 expression were determined to have a high IRS for AR. Statistical analysis revealed that SSEA-4 expression was negatively associated with AR expression in CRPC tissues $(p=0.004)$. However, when a similar analysis was performed with HSPC tissues, no significant relationship was observed in organ-confined, T34N0M0, and metastatic PC ( $p=0.203, p=0.161$, and $p=0.349$, respectively). Therefore, a negative relationship between SSEA-4 and AR was only detected in CRPC tissues.

\section{Discussion}

In the present study, the in vitro studies revealed that SSEA4 was detected in AR-negative PC cell lines (PC3, DU145, and AICaP1), but not in the AR-positive PC cell lines (LNCaP and AICaP2). Additionally, in human PC tissues, SSEA-4 immunoreactivity in CRPC cells was significantly higher than that in high GG (4/5), locally advanced, and metastatic HSPC. In a previous study, we reported that SSEA-4 expression was positively associated with GG, T stage, and metastasis in patients with HSPC (17). Therefore, SSEA-4 was hypothesized to have some crucial roles in CRPC, and its importance in patients with CRPC may be higher than those with HSPC. Nonetheless, our results showed that SSEA-4 was not expressed in AICaP2 even though this cell line was androgen-independent. Furthermore, the malignant potential, which was evaluated by cancer cell
Table I. Relationship between SSEA-4 and the androgen receptor in castration-resistant prostate cancer.

\begin{tabular}{lccc}
\hline & \multicolumn{3}{c}{ Stage-specific embryogenic antigen-4 } \\
\cline { 2 - 4 } Androgen receptor & $+($ mild $)$ & ++ (moderate) & +++ (strong) \\
\hline Immunoreactive score & & & \\
Low (0-5); N/\% & $0 / 0.0$ & $0 / 0.0$ & $5 / 33.3$ \\
Middle (6-8) & $2 / 28.6$ & $3 / 60.0$ & $10 / 77.7$ \\
High (9-12) & $5 / 71.4$ & $2 / 40.0$ & $0 / 0.0$ \\
$\quad p$-Value & & 0.004 & \\
\hline
\end{tabular}

proliferation, migration, and invasion, was significantly higher in AICaP1 cells than in AICaP2 cells. Such findings suggest that SSEA-4 expression in PC cells is associated with complex mechanisms, including the AR signaling system.

Our results revealed an important aspect of the regulatory mechanism of SSEA-4 expression in PC cells. Among our five PC cell lines, SSEA-4 expression was detected in AR-negative PC cells, but not in the AR-positive PC cell lines. Moreover, our in vivo studies using human CRPC tissues demonstrated that SSEA-4 expression was negatively associated with AR expression. Such findings indicate that AR might play crucial regulatory roles in SSEA-4 expression. However, we should simultaneously note that such significant correlation between AR and SSEA-4 was not found in human HSPC tissues. Additionally, our in vitro study showed that the transfection of AR cDNA had no significant effect on SSEA-4 expression in AICaP1 cells. Based on these results, it is indicated that while there exists a negative correlation between AR and SSEA-4 in CRPC, AR status does not directly affect SSEA-4 expression. In fact, various cancer-related factors, including tumor necrosis factor- $\alpha$, mammalian target of rapamycin, and Wnt signaling, have been reported to affect SSEA-4 expression under physiological and pathological conditions $(5,35,36)$.

When the pathobiological significance of SSEA-4 in CRPC is being discussed, it must be noted that SSEA-4 is recognized as a marker of CSCs in a variety of malignancies $(37,38)$. Presently, acquisition of the CSC phenotype is regarded as an important characteristic of CRPC (21). Furthermore, androgen deprivation has been reported to stimulate the reprogramming of PC cells to acquire stem-cell like characteristics $(39,40)$. With regard to the change in SSEA-4 expression caused by hormonal therapy, our results demonstrated that its expression levels were the highest in CRPC, followed by post-NHT tissues, and pre-NHT tissues. In short, SSEA-4 expression was up-regulated by the duration of hormonal therapy. Based on these findings, we hypothesize that the up-regulation of SSEA-4 expression in CRPC reflects the increase in PC cells with stem cell-like characteristics. In fact, the AR-negative phenotype has been 
reported to be essential for maintaining the CSCs of PC and promoting CRPC cells (41), thereby supporting our abovementioned hypothesis that SSEA-4 expression is only detected in the AR-negative PC cell lines.

In recent years, SSEA-4 has been suggested to be a novel therapeutic target in a variety of malignancies (42-44). For example, a mAb directed against SSEA-4 (MC-813-70) has been suggested as a potential therapeutic agent for triplenegative breast cancer cells expressing SSEA-4 (43). Interestingly, our results showed that SSEA-4 was expressed in AR-negative CRPC. Therefore, it is possible that inhibition of SSEA-4 may lead to suppressed cell survival and progression, even though PC cells manage to survive via AR-independent signaling pathways. Based on these findings, we suggest that SSEA-4 is a potential therapeutic target in patients with PC, especially those with CRPC.

Our study has several limitations. First, the number of CRPC tissues was relatively low. Second, the detailed biological and molecular characteristics of our established androgen-independent PC cell lines (AICaP1 and AICaP2) have not been fully elucidated. Lastly, we could not elucidate the detailed interaction between SSEA-4 and AR in CRPC in the current study. Therefore, further studies elucidating the pathological and molecular characteristics of these cell lines are important for their future use.

\section{Conclusion}

Our in vitro studies demonstrated that SSEA-4 was expressed in AR-negative PC cell lines, whereas not expressed in ARpositive ones. In human CRPC tissues, a negative correlation between SSEA-4 and AR was observed. We hypothesize that SSEA-4 is indirectly associated with AR, although the detailed mechanisms of these interactions remain to be fully understood. Additionally, SSEA-4 was expressed in all cases of CRPC tissues and its immunoreactivity level was significantly higher in human CRPC tissues than in HSPC with high GG and metastasis in the descending order of CRPC $>$ post-NHT>pre-NHT tissues. These results indicate that SSEA-4 is a novel biomarker for CRPC, especially ARnegative PC cells. According to previous studies on various malignancies, SSEA-4 might reflect the increased CSC count in CRPC tissues. We suggest that SSEA-4 is a potential therapeutic target in patients with CRPC.

\section{Conflicts of Interest}

The Authors declare no conflicts of interest in relation to this study.

\section{Authors' Contributions}

Study concept: YMi and SS. Study design: YM. In vitro analyses: TT, TS, AI, SS. Clinical data collection: KM, TM, KO. Immunohistochemical analyses: JH, TM, YM, YMu. Statistical analyses: YM, TM. Manuscript preparation: JH, TM, YMi. Manuscript editing: AI, SS. Manuscript review: HS. All Authors read and approved the final manuscript.

\section{Acknowledgements}

This work was supported by a grant from JSPS KAKENHI (grant number: 18K09197 and 19K09713).

\section{References}

1 Isaacs JT: The biology of hormone refractory prostate cancer. Why does it develop? Urol Clin North Am 26(2): 263-273, 1999. PMID: 10361549. DOI: 10.1016/s0094-0143(05)70066-5

2 Mohler ML, Sikdar A, Ponnusamy S, Hwang DJ, He Y, Miller DD and Narayanan R: An overview of next-generation androgen receptor-targeted therapeutics in development for the treatment of prostate cancer. Int J Mol Sci 22(4): 2124, 2021. PMID: 33672769. DOI: $10.3390 /$ ijms22042124

3 Weber M, Hadaschik B, Ferdinandus J, Rahbar K, Bögemann M, Herrmann K, Fendler WP and Kesch C: Prostate-specific membrane antigen-based imaging of castration-resistant prostate cancer. Eur Urol Focus 7(2): 279-287, 2021. PMID: 33483289. DOI: $10.1016 /$ j.euf.2021.01.002

4 Annala M, Vandekerkhove G, Khalaf D, Taavitsainen S, Beja K, Warner EW, Sunderland K, Kollmannsberger C, Eigl BJ, Finch D, Oja CD, Vergidis J, Zulfiqar M, Azad AA, Nykter M, Gleave ME, Wyatt AW and Chi KN: Circulating tumor DNA genomics correlate with resistance to abiraterone and enzalutamide in prostate cancer. Cancer Discov 8(4): 444-457, 2018. PMID: 29367197. DOI: 10.1158/2159-8290.CD-17-0937

5 Zhang W, Ding ML, Zhang JN, Qiu JR, Shen YH, Ding XY, Deng LF, Zhang WB and Zhu J: mTORC1 maintains the tumorigenicity of SSEA-4(+) high-grade osteosarcoma. Sci Rep 5: 9604, 2015. PMID: 25853231. DOI: 10.1038/srep09604

6 Li X, Jiao M, Hu J, Qi M, Zhang J, Zhao M, Liu H, Xiong X, Dong $\mathrm{X}$ and Han B: miR-30a inhibits androgen-independent growth of prostate cancer via targeting MYBL2, FOXD1, and SOX4. Prostate 80(9): 674-686, 2020. PMID: 32294305. DOI: 10.1002/pros.23979

7 Lim SC, Jansson PJ, Assinder SJ, Maleki S, Richardson DR and Kovacevic Z: Unique targeting of androgen-dependent and independent $\mathrm{AR}$ signaling in prostate cancer to overcome androgen resistance. FASEB J 34(9): 11511-11528, 2020. PMID: 32713076. DOI: 10.1096/fj.201903167R

8 Conteduca V, Wetterskog D, Gonzalez-Billalabeitia E, Brighi N, De Giorgi U and Attard G: Circulating androgen receptor for prognosis and treatment selection in prostate cancer. Eur Urol Oncol, 2021. PMID: 33436326. DOI: 10.1016/j.euo.2020.12.009

9 Pisano C, Tucci M, Di Stefano RF, Turco F, Scagliotti GV, Di Maio $\mathrm{M}$ and Buttigliero $\mathrm{C}$ : Interactions between androgen receptor signaling and other molecular pathways in prostate cancer progression: Current and future clinical implications. Crit Rev Oncol Hematol 157: 103185, 2021. PMID: 33341506. DOI: 10.1016/j.critrevonc.2020.103185

10 Leonhard V, Alasino RV, Pasqualini ME, Cremonezzi DC, García NH and Beltramo DM: Monosialoganglioside GM1 reduces toxicity of Ptx and increase anti-metastasic effect in a murine mammary cancer model. Sci Rep 10(1): 10191, 2020. PMID: 32576898. DOI: 10.1038/s41598-020-67256-3 
11 Nazha B, Inal C and Owonikoko TK: Disialoganglioside GD2 expression in solid tumors and role as a target for cancer therapy. Front Oncol 10: 1000, 2020. PMID: 32733795. DOI: 10.3389 /fonc. 2020.01000

12 Sato M, Shimada S, Watanabe M, Kawasaki Y, Sato T, Morozumi K, Mitsuzuka K and Ito A: Expression of ganglioside disialosyl globopentaosyl ceramide in prostate biopsy specimens as a predictive marker for recurrence after radical prostatectomy. Tohoku J Exp Med 252(1): 1-8, 2020. PMID: 32814720. DOI: 10.1620/tjem.252.1

13 Saito S, Orikasa S, Ohyama C, Satoh M and Fukushi Y: Changes in glycolipids in human renal-cell carcinoma and their clinical significance. Int J Cancer 49(3): 329-334, 1991. PMID: 1917130. DOI: $10.1002 /$ ijc. 2910490303

14 Tokuyama S, Saito S, Takahashi T, Ohyama C, Ito A, Kanto S, Satoh M, Hoshi S, Endoh M and Arai Y: Immunostaining of stage-specific embryonic antigen-4 in intratubular germ cell neoplasia unclassified and in testicular germ-cell tumors. Oncol Rep 10(5): 1097-1104, 2003. PMID: 12883664.

15 Zhu LF, Chen QR, Chen SZ, Wang LY, Luo XF, Ren JH, Yuan XH, Wu XQ, Zeng YL, Xiao M, Chen YQ, Chen YY, Lin MH, Wu ZJ, Chen ZZ, Hu JD and Yang T: The Construction and identification of induced pluripotent stem cells derived from acute myelogenous leukemia cells. Cell Physiol Biochem 41(4): 1661-1674, 2017. PMID: 28359056. DOI: 10.1159/ 000471246

16 Chuang PK, Hsiao M, Hsu TL, Chang CF, Wu CY, Chen BR, Huang HW, Liao KS, Chen CC, Chen CL, Yang SM, Kuo CW, Chen P, Chiu PT, Chen IJ, Lai JS, Yu CT and Wong CH: Signaling pathway of globo-series glycosphingolipids and $\beta 1,3$ galactosyltransferase V ( $\beta 3$ GalT5) in breast cancer. Proc Natl Acad Sci USA 116(9): 3518-3523, 2019. PMID: 30808745. DOI: $10.1073 /$ pnas. 1816946116

17 Nakamura Y, Miyata Y, Matsuo T, Shida Y, Hakariya T, Ohba K, Taima T, Ito A, Suda T, Hakomori SI, Saito S and Sakai H: Stage-specific embryonic antigen-4 is a histological marker reflecting the malignant behavior of prostate cancer. Glycoconj J 36(5): 409-418, 2019. PMID: 31243630. DOI: 10.1007/ s10719-019-09882-2

18 Yuno T, Miyata Y, Matsuo T, Mukae Y, Otsubo A, Mistunari K, Ohba K, Suda T, Saito S and Sakai H: Relationship between stage-specific embryonic antigen-4 and anti-cancer effects of neoadjuvant hormonal therapy in prostate cancer. Anticancer Res 40(10): 5567-5575, 2020. PMID: 32988880. DOI: 10.21873/ anticanres.14569

19 Sampayo RG and Bissell MJ: Cancer stem cells in breast and prostate: Fact or fiction? Adv Cancer Res 144: 315-341, 2019. PMID: 31349902. DOI: 10.1016/bs.acr.2019.03.010

20 Contreras HR, López-Moncada F and Castellón EA: Cancer stem cell and mesenchymal cell cooperative actions in metastasis progression and hormone resistance in prostate cancer: Potential role of androgen and gonadotropin releasing hormone receptors (Review). Int J Oncol 56(5): 1075-1082, 2020. PMID: 32319606. DOI: $10.3892 /$ ijo.2020.5008

21 Lin CJ, Lo UG and Hsieh JT: The regulatory pathways leading to stem-like cells underlie prostate cancer progression. Asian J Androl 21(3): 233-240, 2019. PMID: 30178777. DOI: 10.4103/ aja.aja_72_18

22 O'Reilly D, Johnson P and Buchanan PJ: Hypoxia induced cancer stem cell enrichment promotes resistance to androgen deprivation therapy in prostate cancer. Steroids 152: 108497, 2019. PMID: 31521707. DOI: 10.1016/j.steroids.2019.108497

23 Tsao T, Beretov J, Ni J, Bai X, Bucci J, Graham P and Li Y: Cancer stem cells in prostate cancer radioresistance. Cancer Lett 465: 94-104, 2019. PMID: 31493443. DOI: 10.1016/j.canlet. 2019.08.020

24 Miyashita M, Tomogane M, Nakamura Y, Shimizu T, Fujihara A, Ukimura $\mathrm{O}$ and Ashihara E: Sphere-derived prostate cancer stem cells are resistant to $\gamma \delta$ T cell cytotoxicity. Anticancer Res 40(10): 5481-5487, 2020. PMID: 32988870. DOI: 10.21873/ anticanres.14559

25 Cheng J, Yang K, Zhang Q, Yu Y, Meng Q, Mo N, Zhou Y, Yi $\mathrm{X}$, Ma C, Lei A and Liu Y: The role of mesenchymal stem cells in promoting the transformation of androgen-dependent human prostate cancer cells into androgen-independent manner. Sci Rep 6: 16993, 2016. PMID: 26787499. DOI: 10.1038/ srep16993

26 Höfner T, Klein C, Eisen C, Rigo-Watermeier T, Haferkamp A and Sprick MR: Protein profile of basal prostate epithelial progenitor cells - stage-specific embryonal antigen 4 expressing cells have enhanced regenerative potential in vivo. J Cell Mol Med 20(4): 721-730, 2016. PMID: 26849468. DOI: 10.1111 /jcmm.12785

27 Saito S, Levery SB, Salyan ME, Goldberg RI and Hakomori S: Common tetrasaccharide epitope NeuAc alpha $2->3 \mathrm{Gal}$ beta $1 \rightarrow>3$ (Neu-Ac alpha 2->6)GalNAc, presented by different carrier glycosylceramides or O-linked peptides, is recognized by different antibodies and ligands having distinct specificities. J Biol Chem 269(8): 5644-5652, 1994. PMID: 7509790.

28 Lee SO, Dutt SS, Nadiminty N, Pinder E, Liao H and Gao AC: Development of an androgen-deprivation induced and androgen suppressed human prostate cancer cell line. Prostate 67(12): 1293-1300, 2007. PMID: 17626246. DOI: 10.1002/pros.20621

29 Ito A, Levery SB, Saito S, Satoh M and Hakomori S: A novel ganglioside isolated from renal cell carcinoma. J Biol Chem 276(20): 16695-16703, 2001. PMID: 11278988. DOI: 10.1074/ jbc.M011791200

30 Aoki H, Satoh M, Mitsuzuka K, Ito A, Saito S, Funato T, Endoh $\mathrm{M}$, Takahashi $\mathrm{T}$ and Arai $\mathrm{Y}$ : Inhibition of motility and invasiveness of renal cell carcinoma induced by short interfering RNA transfection of beta 1,4GalNAc transferase. FEBS Lett 567(2-3): 203-208, 2004. PMID: 15178323. DOI: 10.1016/ j.febslet.2004.04.060

31 Litvinov IV, Antony L and Isaacs JT: Molecular characterization of an improved vector for evaluation of the tumor suppressor versus oncogene abilities of the androgen receptor. Prostate 61(4): 299-304, 2004. PMID: 15499637. DOI: 10.1002/pros. 20187

32 Mitsunari K, Miyata Y, Asai A, Matsuo T, Shida Y, Hakariya T and Sakai H: Human antigen $\mathrm{R}$ is positively associated with malignant aggressiveness via upregulation of cell proliferation, migration, and vascular endothelial growth factors and cyclooxygenase-2 in prostate cancer. Transl Res 175: 116-128, 2016. PMID: 27140699. DOI: 10.1016/j.trs1.2016.04.002

33 Duan X, Xu X, Yin B, Hong B, Liu W, Liu Q and Tao Z: The prognosis value of EphA3 and the androgen receptor in prostate cancer treated with radical prostatectomy. J Clin Lab Anal 33(5): e22871, 2019. PMID: 30958616. DOI: 10.1002/jcla.22871

34 Saito S, Murayama Y, Pan Y, Taima T, Fujimura T, Murayama K, Sadilek M, Egawa S, Ueno S, Ito A, Ishidoya S, Nakagawa 
H, Kato M, Satoh M, Endoh M and Arai Y: Haptoglobin-beta chain defined by monoclonal antibody RM2 as a novel serum marker for prostate cancer. Int J Cancer 123(3): 633-640, 2008. PMID: 18464263. DOI: 10.1002/ijc.23490

35 Fazzi R, Pacini S, Carnicelli V, Trombi L, Montali M, Lazzarini $\mathrm{E}$ and Petrini M: Mesodermal progenitor cells (MPCs) differentiate into mesenchymal stromal cells (MSCs) by activation of Wnt5/calmodulin signalling pathway. PLoS One 6(9): e25600, 2011. PMID: 21980498. DOI: 10.1371/ journal.pone. 0025600

36 Ueda M, Fujisawa T, Ono M, Hara ES, Pham HT, Nakajima R, Sonoyama W and Kuboki T: A short-term treatment with tumor necrosis factor-alpha enhances stem cell phenotype of human dental pulp cells. Stem Cell Res Ther 5(1): 31, 2014. PMID: 24580841. DOI: $10.1186 /$ scrt420

37 Noto Z, Yoshida T, Okabe M, Koike C, Fathy M, Tsuno H, Tomihara K, Arai N, Noguchi M and Nikaido T: CD44 and SSEA-4 positive cells in an oral cancer cell line HSC-4 possess cancer stem-like cell characteristics. Oral Oncol 49(8): 787-795, 2013. PMID: 23768762. DOI: 10.1016/j.oraloncology. 2013.04.012

38 Ho MY, Yu AL and Yu J: Glycosphingolipid dynamics in human embryonic stem cell and cancer: their characterization and biomedical implications. Glycoconj J 34(6): 765-777, 2017. PMID: 27549315. DOI: 10.1007/s10719-016-9715-x

39 Sánchez BG, Bort A, Vara-Ciruelos D and Díaz-Laviada I: Androgen deprivation induces reprogramming of prostate cancer cells to stem-like cells. Cells 9(6): 1441, 2020. PMID: 32531951. DOI: 10.3390/cells9061441

40 Verma S, Shankar E, Kalayci FNC, Mukunda A, Alassfar M, Singh V, Chan ER, MacLennan GT and Gupta S: Androgen deprivation induces transcriptional reprogramming in prostate cancer cells to develop stem cell-like characteristics. Int J Mol Sci 21(24): 9568, 2020. PMID: 33339129. DOI: 10.3390/ ijms21249568
41 Vummidi Giridhar P, Williams K, VonHandorf AP, Deford PL and Kasper S: Constant degradation of the androgen receptor by MDM2 conserves prostate cancer stem cell integrity. Cancer Res 79(6): 1124-1137, 2019. PMID: 30626627. DOI: 10.1158/00085472.CAN-18-1753

$42 \mathrm{Yu} \mathrm{CC}$, Yu CH and Chang YC: Aberrant SSEA-4 upregulation mediates myofibroblast activity to promote pre-cancerous oral submucous fibrosis. Sci Rep 6: 37004, 2016. PMID: 27845370. DOI: $10.1038 /$ srep37004

43 Ruggiero FM, Rodríguez-Walker M and Daniotti JL: Exploiting the internalization feature of an antibody against the glycosphingolipid SSEA-4 to deliver immunotoxins in breast cancer cells. Immunol Cell Biol 98(3): 187-202, 2020. PMID: 31916611. DOI: 10.1111/imcb.12314

44 Soliman C, Chua JX, Vankemmelbeke M, McIntosh RS, Guy AJ, Spendlove I, Durrant LG and Ramsland PA: The terminal sialic acid of stage-specific embryonic antigen-4 has a crucial role in binding to a cancer-targeting antibody. J Biol Chem 295(4): 1009-1020, 2020. PMID: 31831622. DOI: 10.1074/jbc. RA119.011518
Received May 26, 2021

Revised June 16, 2021

Accepted June 17, 2021 